\title{
DESENVOLVIMENTO DE UMA SITUAÇÃO DE APRENDIZAGEM NO PROCESSO DE RECUPERAÇÃO DE CAPACIDADES NÃO APREENDIDAS PELO ESTUDANTE
}

\author{
Arlete Ehlert de Souza ${ }^{1}$ \\ Juliane Maira Bento² \\ Lilian Elci Claas ${ }^{3}$
}

\section{RESUMO}

\begin{abstract}
Além das mudanças tecnológicas, a sociedade passa por transformações, que reflete também no perfil do estudante da atualidade. Entretanto, a maioria das instituições de ensino ainda emprega o sistema tradicional com sua metodologia ultrapassada ou desatualizada que não proporciona interdisciplinaridade, contextualização de conteúdos e não gera nenhum tipo de estímulo aos estudantes. Desta forma, a educação tem sido foco de grande preocupação, o que tem promovido uma verdadeira revolução na forma com que os docentes estão sendo capacitados. É premente a necessidade de se inovar, lançar mão de novas estratégias de ensino e empregar novas ferramentas pedagógicas. Neste ano implantou-se no SENAI de Jaraguá do Sul uma metodologia diferenciada nos cursos técnicos reestruturados do SENAIsc: as situações de aprendizagem. Uma prática pedagógica que trouxe resultados significativos para os alunos porque contempla atividades desafiadoras, contextualizadas, planejadas e com critérios claros de avaliação. Nesse processo de ensino aprendizagem o educador torna-se, na maior parte do tempo, mediador, e o estudante o responsável pela apropriação do conhecimento em um processo conjunto de trabalho: estudantes, docentes e coordenação de curso e pedagógica. Desta forma, o presente artigo relata uma experiência realizada nos cursos técnicos em vestuário e em produção de moda do Programa Nacional de Acesso ao Ensino Técnico e Emprego (PRONATEC), com a aplicação desta metodologia no processo de apropriação do conhecimento e de avaliação da aprendizagem suplantando os exames para aprovação dos estudantes. Destaca-se, contudo, que os resultados obtidos foram significativos já que garantiram a aprovação de todos os estudantes e satisfação dos que participaram do processo.
\end{abstract}

Palavras-chave: Aprendizagem. Situação de aprendizagem. Prática pedagógica.

\footnotetext{
${ }^{1}$ Especialista, e-mail: aehlert@sc.senai.br

${ }^{2}$ Especialista, e-mail: juliane@sc.senai.br

${ }^{3}$ Especialista, e-mail: lilian@sc.senai.br
} 


\section{INTRODUÇÃO}

Quando se fala no processo de ensino e aprendizagem, muitas têm sido as estratégias e ações que as instituições de ensino lançam mão para que a aprendizagem seja cada vez mais eficaz. A qualidade de ensino deve ser essencial para que o novo profissional possa se inserir no mercado com mais facilidade. Sabe-se que as exigências são muitas e que as pessoas estão cada vez mais críticas e preparadas para exercerem, além da cidadania uma atuação participativa colaborativa, permitindo o desenvolvimento das potencialidades individuais e sociais. Sabe-se que a educação é o alicerce da sociedade e que por meio dela adquire-se o conhecimento necessário para que as pessoas passem por transformações que as levem a interagir adequadamente com o meio em que vivem.

O sistema educacional tradicional precisa mudar, tornar-se mais atrativo e interessante para os estudantes com práticas pedagógicas mais atrativas e inserção de tecnologias educacionais. Entretanto, esses recursos por si só não promovem a aprendizagem do educando. Apesar de toda essa tecnologia e das novas práticas de ensino, o processo de ensino aprendizagem ainda carece de um mediador que saiba empregá-los de acordo com a nova realidade educacional. Desta forma, uma nova proposta didática é o desenvolvimento de competências por meio de situações de aprendizagem.

\section{BASE CONCEITUAL}

Sabe-se que a educação é a grande chave para o desenvolvimento da humanidade e tem sido muito questionada nos últimos tempos, principalmente quanto à necessidade de inovar e diferenciar-se para atender a sociedade moderna e tecnológica, sem perder de foco seu principal objetivo que é a construção do conhecimento. Há uma grande necessidade de se fazer diferente, de ser inovador, integrado e alinhado com a realidade do mercado de trabalho e da sociedade como um todo. Prado $(2012$, p.1) já falava que:

\footnotetext{
Os meios de produção e de serviço estão mudando. A sociedade pósindustrial provavelmente inovará as atividades humanas. [...] Os sistemas de informações tornam-se cada vez mais rápidos e abrangentes por meio das várias mídias. Neste paradigma, o dinamismo e a rapidez da informação requer uma nova forma de pensar a aprendizagem e o conhecimento.
}

Neste contexto, o dinamismo da informação requer em relação à aprendizagem um novo posionamento do professor, que ao entrar em sala de aula terá o desafio de fazer com que seu aluno se aproprie do conhecimento, principalmente quando existem tantas diferenças que vão dos métodos de ensino praticados, das estruturas disponíveis, dos níveis de conhecimento, até as diferenças individuais dos estudantes.

Diante disso, é importante que as mudanças ocorram e que elas possam iniciar pelos professores, hoje atores principais do processo. Os professores precisam rever seus conceitos sobre o processo de ensino e de aprendizagem. É imperativo que deixem de lado as aulas tradicionais e procurem transformá-las em um ambiente interativo, lançando desafios e aproximando os alunos da realidade do mercado e da sociedade. 
Diante de um novo aluno e da necessidade de um novo tipo de professor, as escolas atuais encontram um desafio que há muito tempo não se desenhava: manter-se indispensável. Não é uma tarefa fácil, considerando que a escola atual deve não só atender às demandas que surgiram nos últimos anos - e são muitas - como também preparar-se para um futuro próximo de mudanças tão rápidas e intensas quanto as que ocorrem com o comportamento de seus alunos. Já é rotina em centros urbanos do país, estabelecimentos equipados com internet, que utilizam recursos como diários virtuais e promovem avaliações on-line para atender aos estudantes. Laboratórios estão cada vez mais sofisticados e as ferramentas tecnológicas se multiplicam à disposição dos estudantes.As instituições precisam estar atentas. Existem alunos com diferentes estilos de aprendizagem, alguns aprendem ouvindo, outros vendo e ainda há aqueles que aprendem fazendo e interagindo, analisa Silvia Fichmann. $\mathrm{O}$ uso da tecnologia permite à escola atender a esses diferentes estilos de aprendizagem. (BRISO et al., 2009, p.1),

Hoje a repetição, a transferência de conteúdos, a cópia ou mesmo o ensino repassado de forma singular não faz mais a diferença, afinal isso pode ser realizado através de repetições que já não atendem mais o modelo atual que se quer de aprendizagem.

Quando se fala no processo de ensino e de aprendizagem faz-se necessário lançar mão de estratégias diferenciados de ensino que visem a construção do conhecimento, com o apoio de novas tecnologias. Entre as estratégias de ensino utilizadas atualmente algumas vem se destacando no mundo educacional que são as que propõem a interação e o desafio aos estudantes. É preciso inovar e tornar um agente educacional em um mediador do processo de ensino e de aprendizagem, como aponta Hanze (2007, p.1):

\footnotetext{
A educação como interatividade contempla tempos e espaços novos, diálogo problematização e produção própria dos educandos. O professor exerce a sua habilidade de mediador das construções de aprendizagem. E mediar é intervir para promover mudanças. Como mediador, o docente passa a ser comunicador, colaborador e exerce a criatividade do seu papel de co-autor do processo de aprender dos alunos.
}

Quando falamos no ensino por projetos e, ou por meio de situações de aprendizagem, o objetivo é que se possa promover a integração entre os conteúdos trabalhados em sala e a realidade do mercado proporcionando a interdisciplinaridade. Estas práticas permitem que o aluno construa o seu conhecimento a partir de um contexto que leva em conta vários conhecimentos sem a fragmentação propagada pelo ensino tradicional. Quanto mais os conteúdos estiverem envolvidos numa situação previamente planejada, maior será o desafio, pois os professores também precisarão trabalhar de forma integrada, planejar as etapas estabelecendo cronograma e ter claro os resultados esperados. Outro ponto relevante é a definição dos critérios para avaliação. 
Conforme Valente $(2002$, p. 6):

A solução para uma educação que prioriza a compreensão é o uso de objetos e atividades estimulantes para que o aluno possa estar envolvido com o que faz. Tais alunos e objetos devem ser ricos em oportunidades, que permitam ao estudante explorá-las e, ainda, possibilitar aberturas para o professor desafiá-lo e, com isso, incrementar a qualidade da interação com o que está sendo feito. Uma solução que tem sido bastante explorada atualmente é a educação por meio de projetos educacionais.

Experiências recentes, desenvolvidas dentro dos cursos técnicos do Serviço Nacional de Aprendizagem Industrial (SENAI) de Santa Catarina, têm demonstrado o quanto uma situação de aprendizagem problematizadora pode fazer a diferença na construção do conhecimento dos educandos. Neste tipo de proposta didático-pedagógica o estudante interage permanentemente no processo e aprende a aprender, executando e colocando a "mão na massa", tanto para entender as definições e conceitos que se fazem necessários quanto para construir ou desenvolver um produto. As situações de aprendizagem desenvolvem a capacidade para elaborar textos com mais facilidade, isto porque 0 conteúdo desenvolvido está baseado e suas pesquisas e no relato de experiências.

\subsection{Uma experiência exitosa: CASE atividade integradora como processo de recuperação de capacidades não apreendidas pelo estudante.}

O SENAI de Jaraguá do Sul desenvolve, há alguns anos, atividades integradoras e trabalha com projetos visando o desenvolvimento de conhecimentos, habilidades e atitudes para que o estudante adentre ao mercado de trabalho com competência e se destaque profissionalmente. O Programa Educação em Movimento, por meio da dimensão de formação continuada, vem preparando os docentes para atuar de forma cada vez mais inovadora. Na semana pedagógica que aconteceu em janeiro de 2012, a equipe de apoio pedagógico regional do Departamento Regional (DR) realizou uma capacitação com os docentes que atuam em cursos técnicos reestruturados, sobre a estruturação, desenvolvimento, acompanhamento e avaliação de situações de aprendizagem.

Uma das definições de situação de aprendizagem conforme o Serviço Nacional de Aprendizagem Industrial (2008, p. 29) é:

Entende-se situação de aprendizagem, no âmbito desta proposta de prática pedagógica, como atividade desafiadora que, planejada pedagogicamente, considera a intersecção entre o difícil e o possível para o aluno num determinado momento. Deve ser contextualizada, ter valor sociocultural, evocar saberes e propor a solução de um "problema", que exija tomada de decisão, testagem de hipóteses e transferência de aprendizagens, ampliando no aluno a consciência de seus recursos cognitivos. 
A preparação dos docentes nesta metodologia e sua aplicação no dia a dia em sala de aula é muito importante, pois permite trabalhar de maneira planejada, organizada e integrada propiciando aos estudantes maior envolvimento nas atividades propostas levando-os a construção efetiva do conhecimento. Na situação de aprendizagem, o planejamento das atividades acontece no início do semestre letivo, quando os docentes se reúnem para discutir e definir a situação de aprendizagem para cada turma/semestre baseado nas competências requeridas pelo módulo e, a partir delas são listadas as atividades, resultados esperados e os critérios de avaliação.

Nesta etapa, cada detalhe deve ser bem analisado, pois os conteúdos das unidades curriculares são trabalhados de forma integrada buscando a construção globalizada das partes. Seu desenvolvimento e aplicação é um desafio para os docentes, assim como para os estudantes, que aprendem através de práticas muito próximas da realidade das empresas. Este aprender fazendo permite que os alunos produzam, questionem, pesquisem, criem, compreendam, interpretem e até mesmo descubram novos conhecimentos, como cita Prado (2009 apud Freire e Prado, 1995, p. 3):

[...] uma situação de aprendizagem deve propiciar ao aluno a vivenciar ações reflexivas, que possa favorecer tanto aprender-com, como aprender-sobre o pensar. Isto significa que o aluno deve aprender-fazendo (colocando a mão na massa) e construindo algo que the seja significativo, de modo que posso envolver-se afetiva e cognitivamente com aquilo que está sendo produzido. É importante que o produto seja algo tangível e passível de ser feito e compreendido pelo aluno-produtor; algo que permita ao aluno reconhecer durante o processo de produção, uma utilidade imediata para aquilo que esta sendo feito e aprendido.

As situações de aprendizagem devem ser desafiadoras, mas possíveis de serem realizadas, uma vez que o objetivo principal é o aprendizado do estudante. A seleção do uso de estratégias de ensino adequadas na realização da situação de aprendizagem deve permitir ensaios, testes, trabalhos de pesquisa, práticas diversas que promovam êxito nos resultados esperados.

O Serviço Nacional de Aprendizagem Industrial (2009, p.60) destaca a importância do planejamento nas atividades de ensino:

\begin{abstract}
A seleção de estratégias para o desenvolvimento de uma situação de aprendizagem exige que o docente leve em consideração dois aspectos: a adequação de cada uma delas para o que se quer desenvolver, considerandose a qualidade do desempenho que se deseja do aluno e a economia do tempo que se pode fazer; e a carga horária disponível para o desenvolvimento da situação de aprendizagem completa (algumas estratégias levam mais rapidamente ao resultado, enquanto outras exigem mais tempo).
\end{abstract}

Uma vez definidas as estratégias para que sejam assertivas, quando no momento da sua aplicação, os docentes acompanham os estudantes na construção da situação de aprendizagem e analisam a efetividade delas no processo corrigindo os desvios quando necessário. $O$ docente como mediador do processo durante esta fase também detecta as 
necessidades dos estudantes e possibilita, se necessário, à recuperação de conteúdos não apreendidos ou não desenvolvidos durante o módulo, o que permite o desenvolvimento das capacidades necessárias a sua formação, conforme aponta o perfil profissional.

Aplicada desde 2012, nos cursos técnicos reestruturados, a situação de aprendizagem tem sido muito eficaz, apresentando resultados significativos nas turmas as quais são inseridas. Do ponto de vista dos docentes que atuam com a situação de aprendizagem ela inicialmente foi muito questionada quanto à conclusão da atividade e o alcance dos resultados esperados. Pois, as situações de aprendizagem exigiram várias horas de planejamento para o alinhamento e realinhamento das atividades, orientação e acompanhamento permanente do cronograma e dos resultados alcançados em cada etapa. Em função da conjunção dos esforços de todos (professores, coordenação e estudantes) os resultados foram compensadores, pois ficou evidente o crescimento e a apropriação dos conhecimentos, bem como a sua satisfação com os resultados alcançados por parte dos estudantes. Entretanto, os docentes reconhecem que mesmo a situação de aprendizagem tendo apresentado sucesso, a mesma pode ser lapidada para ser aplicada em outras turmas, o que pode gerar resultados ainda melhores.

\begin{abstract}
Além disso, é necessário compreender que não é preciso simplificar tudo o que se oferece aos alunos, pois eles podem enfrentar objetos de conhecimento complexos, desde que o docente respeite e apoie a forma como vão enfrentando esta complexidade. Assim, passamos a poder abrir a escola para o mundo e fazer dela um ponto de partida da aventura do conhecimento e nunca o ponto de chegada.
\end{abstract}

Portanto, planejar requer do docente:

- Estar aberto para acolher o aluno e sua realidade;

- Estabelecer prioridades e limites, tendo em vista o desenvolvimento de capacidades e o tempo disponível para isso;

- Pesquisar sempre;

- Ser criativo na elaboração das situações de aprendizagem;

- Ser flexível para replanejar sempre que necessário. (SENAI, 2008, p.32)

Já as coordenadoras dos cursos consideram que uma situação de aprendizagem, quando bem elaborada e planejada, pode contemplar todas as unidades curriculares de um semestre, gerando interdisciplinaridade, tornando-se norteadora para a apropriação dos conhecimentos requeridos na competência dos módulos. O planejamento desse tipo de atividade deve incluir uma série de atividades complementares como pesquisas, trabalhos em grupo, experimentos, etc., que contribuam para que o estudante investigue aplique e construa o conhecimento. 
Como o desenvolvimento de competências requer a utilização de uma gama variada de estratégias de ensino, o docente, ao selecioná-las, deve preferencialmente escolher aquelas que deem oportunidade ao trabalho em equipe, propiciem uma atitude dialógica, a troca de informações entre os alunos e entre alunos e docente. Na verdade, instiguem e estimulem a aprendizagem, despertando o interesse pela busca dos saberes, tendo em vista a solução de situações desafiadoras. (SENAI, 2008, p.36)

Além disso, segundo a coordenação, as situações de aprendizagem proporcionam clareza no processo de avaliação evidenciando as limitações individuais permitindo que os docentes propiciem atividades paralelas de recuperação no decorrer do processo. Outro aspecto que merece destaque é que os trabalhos e provas, que permitem a aprovação de um estudante com a apropriação de apenas $70 \%$ dos conhecimentos requeridos no módulo deixam de ser o único ponto de referência para a avaliação de um processo de aprendizagem.

Uma situação de aprendizagem direciona os estudantes para o cumprimento de cada uma das etapas da atividade, entretanto, por vezes, quando um deles não atinge o desempenho esperado pode-se oportunizar uma atividade de recuperação com outras técnicas ou abordagens. Desta forma estabelecem-se novos prazos e, se o estudante atinge o desempenho esperado, é desnecessária a realização de exames finais. Esta sistemática é reforçada e defendida por SENAI (2008, p.37)

Elaborada a situação de aprendizagem, o docente deve definir critérios de avaliação que the permitam coletar informações sobre os desempenhos do aluno. Posto de outra forma, a pretensão é saber se o aluno está alcançando ou não, nas avaliações formativa e somativa, os resultados esperados.

Como esta metodologia trouxe uma aprendizagem significativa para os estudantes dos cursos técnicos reestruturados do SENAI Jaraguá do Sul, a coordenação do curso técnico em Produção de Moda desafiou seu grupo de docentes a planejar uma atividade semelhante para ser aplicada como forma de avaliação no final do módulo do referido curso, uma vez que alguns alunos não haviam alcançado a competência requerida.

Como essa metodologia apresentou resultados efetivos resolveu-se adaptá-la para ser aplicada no lugar dos tradicionais exames finais nos cursos técnico em Vestuário e técnico em Produção de Moda do programa PRONATEC. Ao final do 1ㅇs semestre de 2012, após o conselho de classe final destes cursos, identificou-se que $31 \%$ dos estudantes (gráfico 1) estavam em exame porque não conseguiram desenvolver as competências requeridas pelo módulo para serem considerados aprovados. Elaborou-se, então, uma semana de atividades práticas usando a metodologia da situação de aprendizagem voltada para uma situação real de mercado com o objetivo de auxiliar os estudantes a se apropriarem dos conhecimentos que ainda faltavam, sem que fosse necessária a realização de um exame elaborado de forma tradicional com a mera intenção de medir para aprovar ou reprovar. 


\section{percentual de aprovação}

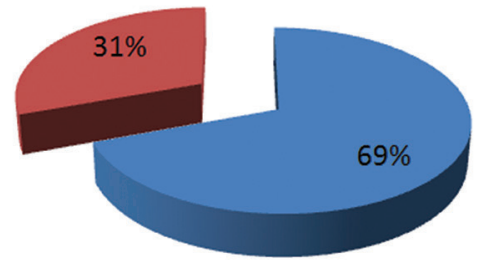

घestudantes aprovados

n estudantes em exame

Fonte: Das autoras (2012)

De posse dessa informação a preocupação, tanto da coordenação dos cursos quanto dos professores, estava relacionada com a aprendizagem destes estudantes, pois o fato de realizar uma avaliação final não demonstraria efetivamente o aprendizado e ainda havia o risco de haver reprovações.

Infelizmente o processo de ensino aprendizagem tradicional empregado nestas duas turmas não foi capaz de atender as necessidades específicas destes estudantes e, por isso, era premente realizar alguma atividade que fosse capaz de reverter esse quadro, apesar de ser no final de um semestre inteiro de trabalho.

Cabe aqui ressaltar ainda que isso também foi motivo de reflexão sobre as práticas de ensino empregadas durante o semestre que não foram suficientes para dar suporte ao desenvolvimento das competências requeridas.

O desafio da equipe de trabalho era fazer com que os estudantes se apropriassem do conhecimento na sua íntegra, e não apenas uma parcela deles. Decidiu-se que era preciso auxiliá-los a construírem seu conhecimento em um curto espaço de tempo.

Assim, foi aplicada a situação de aprendizagem visando suprir a necessidade apresentada pelos educandos, substituindo o tradicional exame. A atividade proposta seria baseada nas dificuldades apresentadas pelos estudantes nas unidades curriculares do semestre.

Os gráficos 2 e 3, apresentam as unidades curriculares que precisavam de reforço em cada curso técnico em questão. Este levantamento foi realizado em sala de aula com os estudantes. 
Gráfico 2: Unidades curriculares do curso Técnico em Vestuário
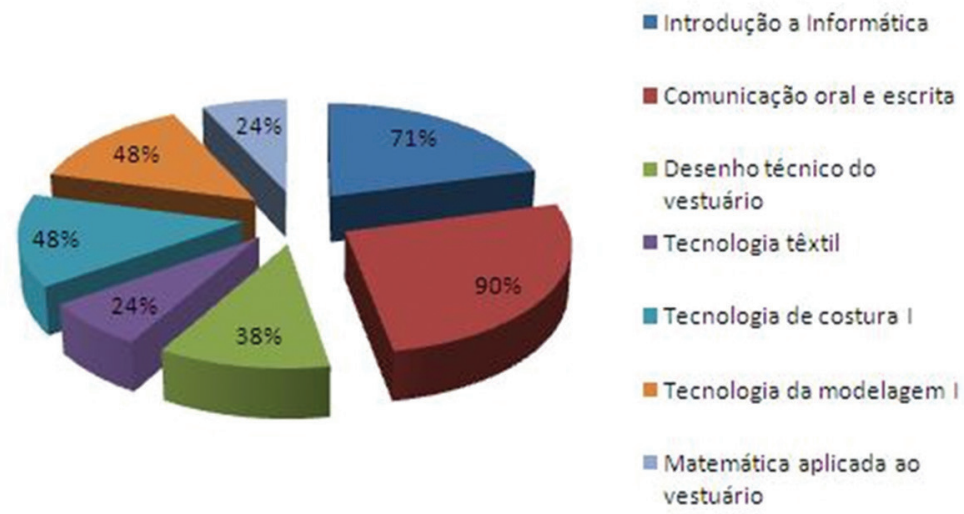

Fonte: Das autoras (2012)

Gráfico 3: Unidades curriculares do curso Produção de Moda
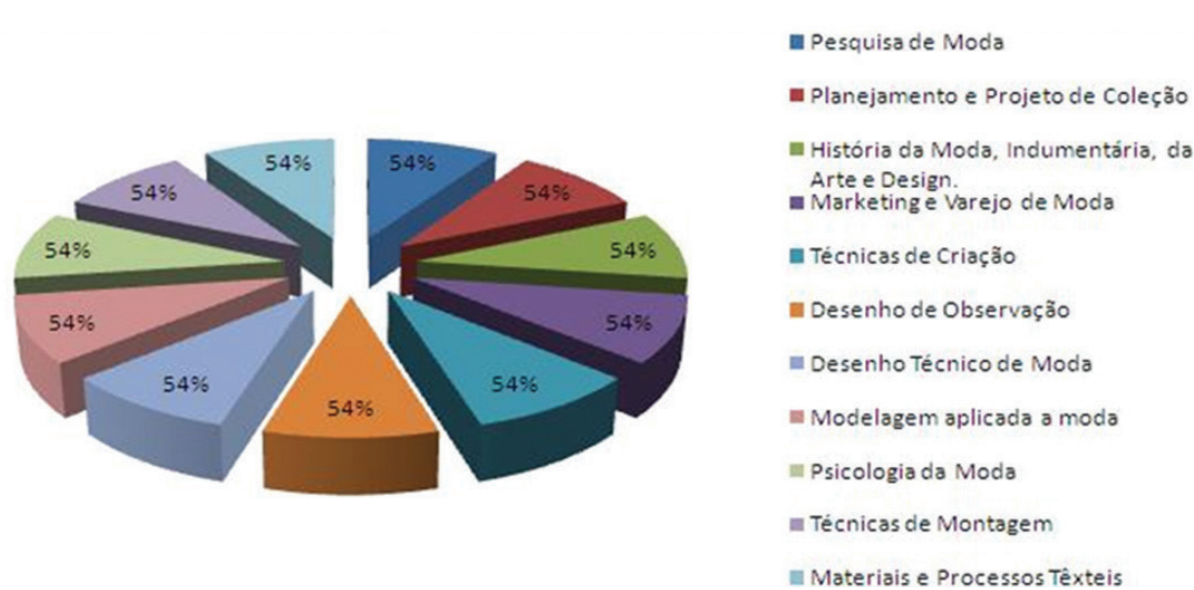

Fonte: Das autoras (2012)

No curso Técnico em vestuário, gráfico 2 , as unidades de comunicação oral e escrita e informática destacaram-se por apresentar os percentuais de $90 \%$ e $71 \%$ respectivamente, essas unidades curriculares são seguidas pelas tecnologias de costura e modelagem.

No técnico em produção de moda, gráfico 3, os percentuais foram iguais na maioria das unidades curriculares. Este percentual foi gerado após os alunos serem questionados quanto a sua percepção em necessidade de reforço de aulas.

Os gráficos 4 e 5 apresentam os resultados relativos a proporção de estudantes que ficaram em exame nos dois cursos técnicos em questão. 
Gráfico 4: Percentual de alunos que ficaram em exame no curso técnico do vestuário

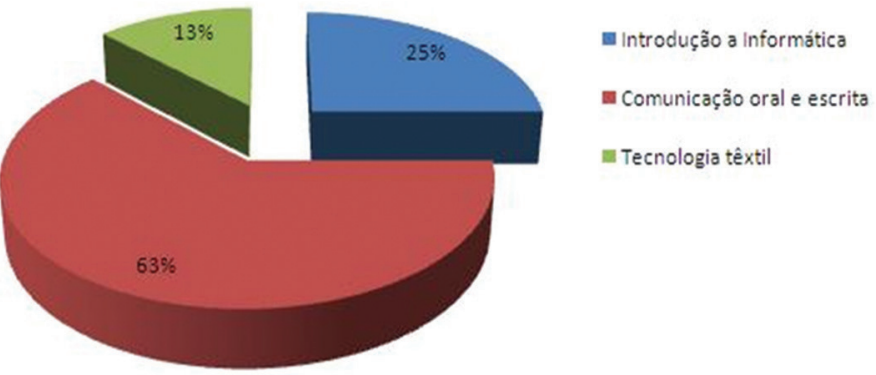

Fonte: Das autoras (2012)

Gráfico 5: Percentual de alunos que ficaram em exame no curso técnico em Produção de Moda

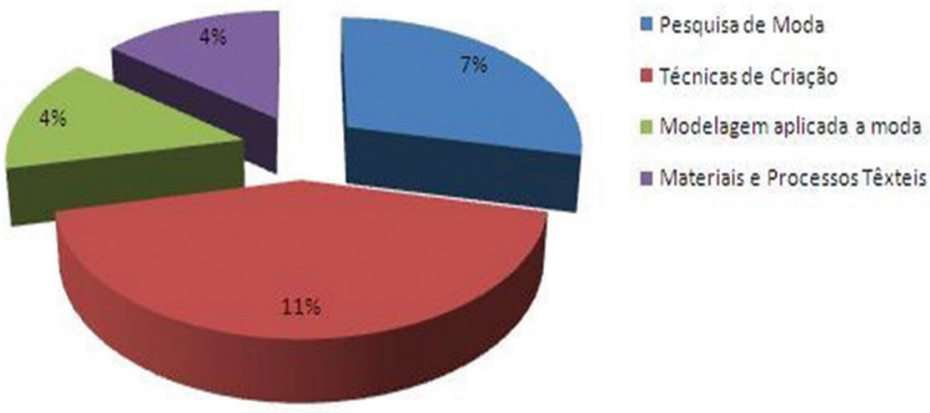

Fonte: Das autoras (2012)

Segundo o que apresentam os gráfico 4 e 5, as unidades curriculares que, na percepção dos estudantes, precisavam de reforço, são praticamente as mesmas identificadas pelos docentes: comunicação oral e escrita, introdução a informática e tecnologia têxtil no técnico em vestuário e, técnicas de criação, pesquisa de moda, modelagem e materiais têxteis no técnico em produção e moda. Isso demonstra claramente que os estudantes têm clareza sobre onde residem suas dificuldades.

Dessa forma, era imperativo identificar e alinhar os conhecimentos das unidades curriculares a serem resgatadas e os conteúdos para o desenvolvimento das competências requeridas. Assim, planejou-se uma situação de aprendizagem capaz de contemplar todos os aspectos a serem desenvolvidos que resultasse em uma atividade que representasse a apropriação dos conhecimentos e da competência do módulo em questão. Para isso, estabeleceram-se as estratégias, os pontos a serem trabalhados e os critérios de avaliação que foram divulgados aos estudantes. 
O planejamento foi um momento onde várias ideias interessantes afloraram, mas era preciso tomar cuidado para definir uma atividade adequada para a situação em questão. Além disso, era necessário que a atividade fosse atrativa para os estudantes e que eles pudessem desenvolvê-la com motivação e, não apenas para cumprir mais uma etapa obrigatória do processo de aprovação.

Desta forma, os maiores desafios foram integrar as diversas unidades curriculares, desenvolver uma situação contextualizada, docente apenas como mediador do processo, atratividade da proposta de trabalho e período de execução de apenas uma semana.

Em depoimento, um dos docentes afirmou que "definir cada uma das etapas do trabalho foi fundamental, pois permitiu saber onde se queria chegar, como seria realizada cada etapa, quais os critérios de avaliação que seriam adotados e também como a atividade seria repassada para os alunos. Planejar é sem dúvida um momento de analisar o todo e poder ser o mais assertivo possível na hora da sua implantação". (Informação verbal ${ }^{4}$ ).

Para os estudantes do curso técnico em Produção de Moda - PRONATEC estabeleceuse que a atividade seria o desenvolvimento de uma coleção de acessórios do vestuário para o verão 2013. Já para os estudantes do Curso Técnico em Vestuário - PRONATEC a atividade consistia em confeccionar uma peça do vestuário e customizá-la.

O quadro 1 apresenta a descrição do planejamento das atividades do curso técnico em vestuário.

Quadro 1: Planejamento das atividades constantes na Situação de Aprendizagem e respectivos resultados esperados no curso técnico em vestuário

\begin{tabular}{|c|c|c|c|}
\hline \multicolumn{4}{|c|}{ Técnico em Vestuário } \\
\hline Descrição das atividades & Resultados esperados & $\begin{array}{l}\text { Unidade } \\
\text { Curricular }\end{array}$ & $\begin{array}{l}\text { Tempo } \\
\text { estimado }\end{array}$ \\
\hline $\begin{array}{l}\text { Digitar relatórios } \\
\text { Elaborar uma apresentação } \\
\text { em Power point }\end{array}$ & $\begin{array}{l}\text { Relatório técnico } \\
\text { Apresentação final das } \\
\text { atividades realizadas na } \\
\text { semana }\end{array}$ & $\begin{array}{l}\text { Introdução a } \\
\text { Informática }\end{array}$ & $4 \mathrm{~h}$ \\
\hline Redigir relatório & Redação & $\begin{array}{l}\text { Comunicação } \\
\text { oral e escrita }\end{array}$ & $4 \mathrm{~h}$ \\
\hline $\begin{array}{l}\text { Fazer o desenho técnico } \\
\text { de um "botton" (camiseta } \\
\text { básica) e do processo de } \\
\text { customização }\end{array}$ & $\begin{array}{l}\text { Desenho técnico da } \\
\text { camiseta } \\
\text { Camiseta customizada }\end{array}$ & $\begin{array}{l}\text { Desenho } \\
\text { técnico do } \\
\text { vestuário }\end{array}$ & $4 \mathrm{~h}$ \\
\hline
\end{tabular}

4 Relato de entrevistado concedido em SC, 2012. 


\begin{tabular}{|c|c|c|c|}
\hline \multicolumn{4}{|c|}{ Técnico em Vestuário } \\
\hline Descrição das atividades & Resultados esperados & $\begin{array}{l}\text { Unidade } \\
\text { Curricular }\end{array}$ & $\begin{array}{c}\text { Tempo } \\
\text { estimado }\end{array}$ \\
\hline $\begin{array}{l}\text { Selecionar material } \\
\text { adequado para costurar a } \\
\text { camiseta }\end{array}$ & $\begin{array}{l}\text { Matéria prima para } \\
\text { confeccionar a camiseta }\end{array}$ & $\begin{array}{l}\text { Tecnologia } \\
\text { têxtil }\end{array}$ & $2 \mathrm{~h}$ \\
\hline $\begin{array}{l}\text { Riscar, cortar e costurar, } \\
\text { dentro dos padrões de } \\
\text { qualidade, os protótipos } \\
\text { definidos }\end{array}$ & $\begin{array}{l}\text { Camiseta cortada } \\
\text { Peça costurada com } \\
\text { qualidade }\end{array}$ & $\begin{array}{l}\text { Tecnologia de } \\
\text { costura I }\end{array}$ & $4 h$ \\
\hline Analisar molde da camiseta & Molde pronto & $\begin{array}{l}\text { Tecnologia da } \\
\text { modelagem I }\end{array}$ & $4 \mathrm{~h}$ \\
\hline
\end{tabular}

Fonte: Das autoras (2012)

O quadro 2 apresenta a descrição do planejamento das atividades do curso Técnico em produção de moda.

Quadro 2: Planejamento das atividades constantes na Situação de Aprendizagem e respectivos resultados esperados no curso técnico em produção de moda

\begin{tabular}{|l|l|l|l|}
\hline \multicolumn{2}{|c|}{ Técnico em Vestuário } \\
\hline $\begin{array}{l}\text { Descrição das atividades } \\
\text { do vestuário com } \\
\text { propostas de técnicas } \\
\text { para aproveitamento de } \\
\text { material e customização }\end{array}$ & $\begin{array}{l}\text { Resultados esperados } \\
\text { customizadas }\end{array}$ & $\begin{array}{l}\text { Unidade } \\
\text { Curricular }\end{array}$ & $\begin{array}{l}\text { Tempo } \\
\text { estimado }\end{array}$ \\
$\begin{array}{l}\text { Realizar pesquisa nas } \\
\text { macro e micro tendências } \\
\text { do verão 2013 e definir um } \\
\text { tema para coleção }\end{array}$ & $\begin{array}{l}\text { Painéis para inspiração } \\
\text { para desenvolver os } \\
\text { acessórios (verão 2013) }\end{array}$ & $\begin{array}{l}\text { Pesquisa de } \\
\text { criação }\end{array}$ & moda \\
$\begin{array}{l}\text { Definir uma marca para } \\
\text { coleção e a forma de } \\
\text { apresentação dos produtos }\end{array}$ & $\begin{array}{l}\text { Tema da coleção } \\
\text { Marca da coleção }\end{array}$ & Comercialização & Marketing \\
\hline
\end{tabular}


Técnico em Vestuário

\begin{tabular}{|c|c|c|c|}
\hline \multicolumn{4}{|c|}{ Técnico em Vestuário } \\
\hline Descrição das atividades & Resultados esperados & $\begin{array}{l}\text { Unidade } \\
\text { Curricular }\end{array}$ & $\begin{array}{l}\text { Tempo } \\
\text { estimado }\end{array}$ \\
\hline $\begin{array}{l}\text { Fazer o molde dos produtos } \\
\text { definidos na pesquisa }\end{array}$ & $\begin{array}{l}\text { Moldes das bolsas } \\
\text { e demais acessórios } \\
\text { definidos }\end{array}$ & Modelagem & $2 \mathrm{~h}$ \\
\hline $\begin{array}{l}\text { Costurar e customizar os } \\
\text { produtos definidos }\end{array}$ & Peças costuradas & $\begin{array}{l}\text { Técnicas de } \\
\text { montagem }\end{array}$ & $4 h$ \\
\hline Elaborar um book & Apresentação do book & $\begin{array}{l}\text { Planejamento } \\
\text { e projeto }\end{array}$ & $6 \mathrm{~h}$ \\
\hline
\end{tabular}

Fonte: Das autoras (2012)

Apesar de ser uma atividade direcionada para suprimir o exame final, estendeuse o convite para todos os estudantes das turmas em questão, que prontamente se dispuseram a participar, entretanto, $50 \%$ não participou no primeiro dia. Infelizmente alguns, não se sentiram motivados o suficiente e não participaram da atividade, o que já era esperado uma vez que muitos já tinham outros compromissos e já estavam satisfeitos com o desempenho alcançado no semestre. Os gráficos 6 e 7, demonstram número e o percentual de participação geral de cada turma.

Gráfico 6: Alunos participantes na atividade desenvolvida

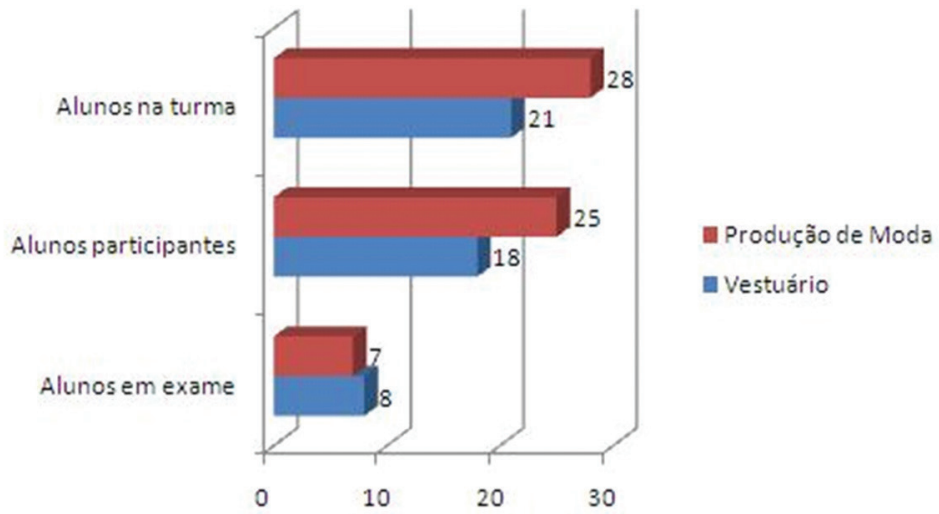

Fonte: Das autoras (2012) 


\section{\% de Participação}

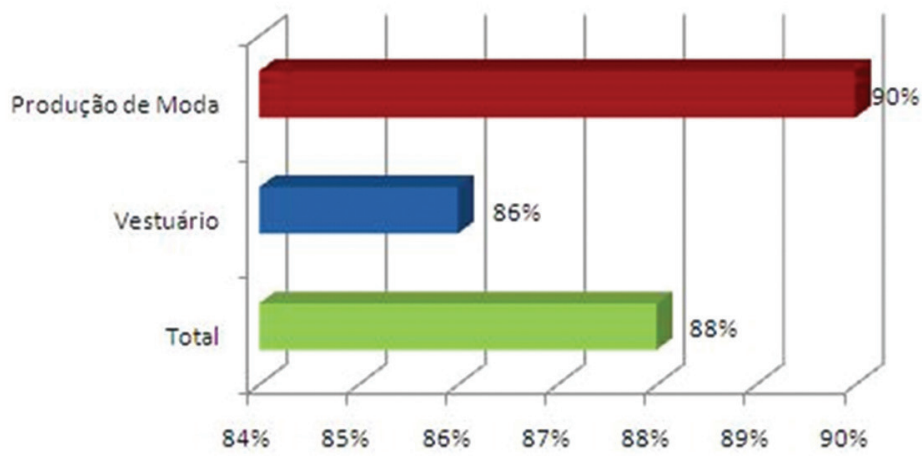

Fonte: Das autoras (2012)

Para que a atividade pudesse ser realizada em uma semana era essencial respeitar o tempo de produção de cada aluno e, por isso, definiu-se que a atividade seria acompanhada por dois docentes a cada dia. Enquanto um estudante estava na etapa " $X$ " o outro já se encontrava na etapa " $Y$ ".

O processo de mediação docente aconteceu quase que naturalmente. Uma das docentes que atua nos dois cursos técnicos acompanhou os estudantes em todo o processo de desenvolvimento da atividade e achou o envolvimento fantástico. Ressaltou a docente que "como cada estudante participou efetivamente do trabalho, foi muito interessante vê-los preocupados com o resultado final, produzindo, construindo. O comprometimento do grupo na atividade era grande, estavam muito unidos, se ajudavam nas dificuldades". (Informação verbal ${ }^{5}$ ).

Para a realização da atividade proposta foram utilizadas diversas estratégias de ensino como: aulas expositivas reforçando os conceitos teóricos, palestras, construção de textos (relatórios e apresentações) e práticas de laboratório.

Quando a proposta de trabalho foi apresentada os estudantes ficaram maravilhados, pois teriam, pela primeira vez, a oportunidade de recuperar conteúdo, reforçar o aprendizado e ainda realizar uma atividade prática próximo a uma realidade de mercado. $\mathrm{O}$ empenho e o comprometimento foi grande, superando as expectativas iniciais da equipe de docentes que os acompanhavam.

O que mais surpreendeu a equipe de docentes e a coordenação dos cursos foi a forma com que os estudantes se envolveram na atividade. Inicialmente só vieram os alunos que estavam em exame em uma unidade curricular, mas como ficaram empolgados utilizaram rede social para convidar os demais colegas a participar deste processo. No segundo dia de atividade já estavam presentes quase $100 \%$ dos estudantes.

5 Relato de entrevistado concedido em SC, 2012. 
Os estudantes do curso técnico em Produção de Moda - PRONATEC fizeram um desfile para apresentar sua coleção e tomaram o cuidado de preparar cada uma das etapas. Um book da coleção foi confeccionado pelos alunos, ou seja, foram além do que havia sido estabelecido na proposta. As figuras 2 e 3 apresentam algumas fotos dos momentos vividos pelas duas turmas na realização da atividade.

Figura 1: Atividades realizadas pelos estudantes do curso técnico de produção de moda

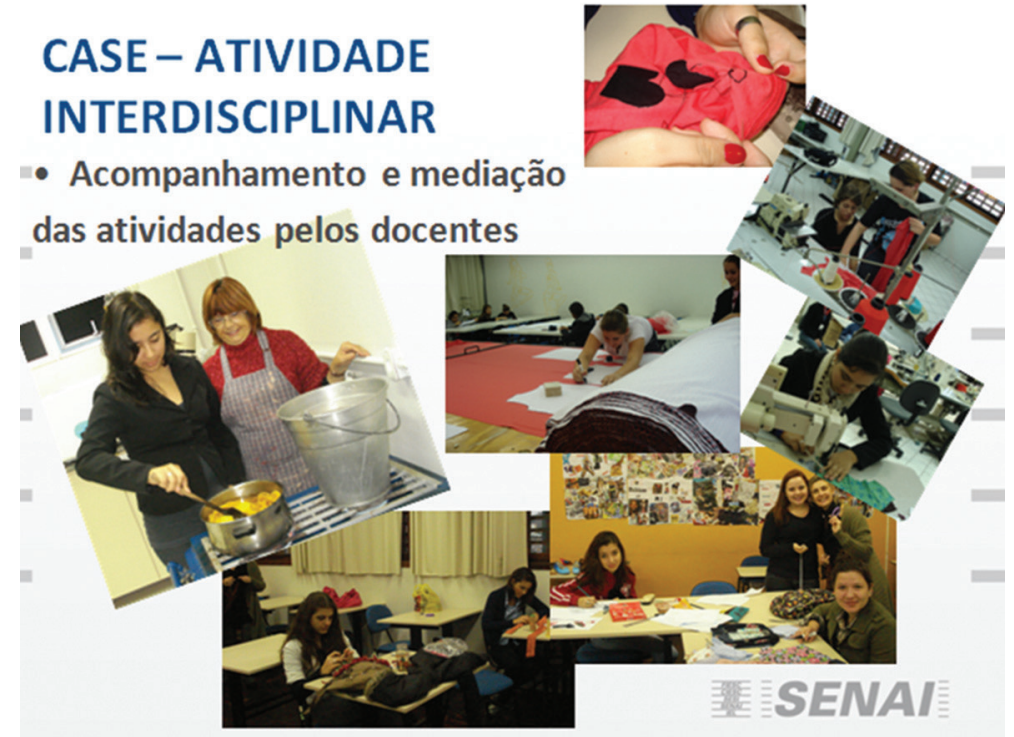

Fonte: Das autoras (2012)

Os estudantes do Curso Técnico em Vestuário - PRONATEC após customizarem suas peças fizeram um relatório final falando sobre as atividades da semana e uma apresentação da sua produção. Segundo a docente de comunicação oral e escrita, a evolução dos estudantes foi surpreendente.

Os docentes foram avaliando cada etapa do processo durante toda a semana e para a apresentação final convidaram outros docentes, a coordenação do curso e a coordenação pedagógica para socializar o que desenvolveram na semana de trabalho.

A coordenação dos cursos também ficou satisfeita com o resultado e o que mais Ihe chamou a atenção foi o desempenho de uma aluna que aparentemente mostrava problemas de aprendizagem. A aluna superou suas limitações e dificuldades, conseguindo cumprir todas as etapas e produzir sua peça. Durante sua apresentação emocionou os docente quando agradeceu a oportunidade de ter realizado esta atividade dizendo o quanto foi significativo para ela ter participado deste processo e o quanto realmente aprendeu. 
Figura 2: Apresentação dos estudantes

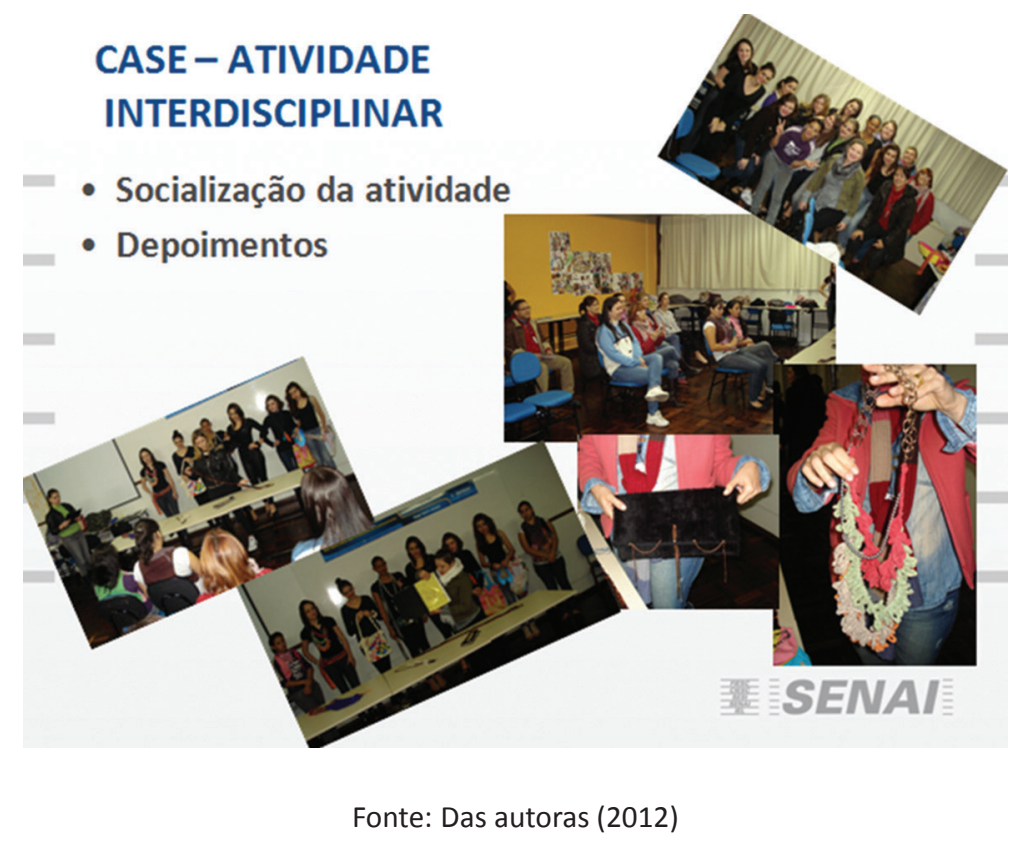

Ao término da semana e com a conclusão das atividades todos os alunos foram aprovados e os professores ficaram satisfeitos com o envolvimento e o comprometimento de todos nas atividades propostas. A aprendizagem efetivamente ocorreu e o resultado foi muito maior do que o esperado. O que mais gratificou os docentes e a coordenação dos cursos foi ouvir o depoimento dos estudantes ao afirmarem que esta atividade foi muito boa, pois o ganho em termos de aprendizagem foi significativo. Além disso, afirmaram que ter a oportunidade de fazer um exame de forma diferenciada os deixou motivados e mais seguros para realizar a avaliação proposta. Outros falaram que a atividade despertou $o$ sentimento de "quero mais", motivando-os a permanecerem no curso e curiosos para saber o que será desenvolvido nos próximos semestres.

Uma das alunas do curso técnico em Vestuário (PRONATEC), que participou da atividade a convite dos docentes, apesar de não necessitar participar desse processo de avaliação final, em depoimento afirmou que "foi muito bom participar desta atividade, pois tivemos a oportunidade de reforçar o conteúdo aprendido e ainda vermos algo a mais como customizar uma peça do vestuário. Na minha visão é Importante ver o resultado final do produto, como ele fica e que cuidados deve-se ter para que ele fique com uma boa qualidade".(Informação verbal $\left.{ }^{6}\right)$.

6 Relato de entrevistado concedido em SC, 2012. 
Já a aluna, do curso técnico em Produção de Moda (PRONATEC) em depoimento afirmou que "fazer o exame desta forma diferenciada a envolveu mais no curso, pois teve a oportunidade de aplicar seus conhecimentos e construir um produto que foi apresentado em um pequeno desfile. Isso me deu mais vontade de continuar no curso. Estou ansiosa para ver como será o próximo semestre". (Informação verbal7).

Outra aluna do mesmo curso, relatou que "quando percebi que a atividade seria interessante e também aprenderíamos mais ainda com a proposta apresentada convidei meus colegas pelo facebook onde temos um grupo, pois queria que eles participassem desta atividade junto comigo". (Informação verbal ${ }^{8}$ ).

Já a aluna do curso técnico em vestuário que apresenta certas dificuldades de aprendizagem falou que para ela foi fundamental ter esta nova oportunidade, pois ela sabe de suas limitações e a maneira que foi trabalhada a atividade conseguiu aprender, de uma forma diferente, o que antes não havia ficado tão claro. (Informação verbal ${ }^{9}$ ).

Nesta experiência os alunos participaram efetivamente e os resultados apresentados foram muito bons, sendo que os estudantes ficaram satisfeitos com o trabalho que desenvolveram e os docentes encantados com a aprendizagem efetiva dos alunos. Os docentes lados imaginavam que os estudantes apresentariam muitas dificuldades e se questionavam se conseguiriam alcançar o resultado esperado. Como qualquer projeto desenvolvido pela primeira vez, este também precisa de alguns ajustes e, por isso, faz-se necessário replanejar alguns aspectos como: a definição do cronograma, estabelecendo além das datas a quantidade de horas necessárias para cada tarefa e reuniões intermediárias para análise do resultado parcial.

A satisfação com o trabalho desenvolvido é imensa enche-nos de orgulho por fazermos parte do grupo de educadores do SENAI de Jaraguá do Sul. Ser reconhecido como um educador e fazer a diferença na vida de um indivíduo são a maior fonte de motivação de um professor e isso ficou evidente na realização dessa atividade. Ela exige muito do grupo de trabalho, entretanto, vale a pena porque além de cumprir um requisito do processo de aprovação, é possível desenvolver e consolidar os conhecimentos requeridos. Cabe destacar que a opção por esta abordagem permitiu que todos os estudantes fossem aprovados no semestre em questão e não limitou-se apenas ao cumprimento de uma formalidade acadêmica, que eventualmente, não obteria o mesmo resultado.

7 Relato de entrevistado concedido em SC, 2012.

8 Relato de entrevistado concedido em SC, 2012.

9 Relato de entrevistado concedido em SC, 2012. 
Não existem limites quando o assunto é educação, basta que pessoas ousem e façam a diferença. O processo de ensino e de aprendizagem precisa acontecer de forma mais natural e voltada as necessidade dos estudantes para que possam ultrapassar as fronteiras, sair da rotina e mudar o tradicional. Isso ficou evidente quando o grupo decidiu empregar a metodologia da situação de aprendizagem no processo de recuperação de conteúdos ao invés de aplicar o exame. Ver o resultado final, a satisfação dos professores, a motivação dos estudantes nas tarefas e principlamente perceber que houve aprendizagem significativa faz com que reflitamos sobre as nossas práticas tradicionais de ensino, pois precisamos inovar. A metodologia tradicional de ensino não se encaixa mais na realidade atual, faz-se necessário mudanças. É preciso desenvolver novas técnicas e mobilizar docentes e estudantes a aprender a aprender, ou seja, o conhecimento precisa ser permanente para todos.

Diante do exposto, os benefícios deste trabalho foram muitos. A instituição porque promoveu um ensino contextualizado e aprovou $100 \%$ dos alunos em exame, os docentes porque conseguiram superar junto com os estudantes as limitações e as dificuldades tornando-se assim referenciais de competência, de respeito, de admiração por parte dos estudantes, dos colegas de trabalho e da instituição. E isso é fonte de motivação para qualquer docente que tem amor a profissão e ao ser humano. Ganharam os estudantes porque eles superaram suas limitações, desenvolveram competências e motivaram-se a continuar os estudos.

\title{
DEVELOPMENT OF A LEARNING SITUATION IN THE PROCESS OF RECOVERY OF CAPACITY NOT SEIZED BY THE STUDENT
}

\begin{abstract}
Apart from technological changes, society goes through transformations, which today also reflects on the student profile. However, most educational institutions still employs the traditional system with its outmoded or outdated methodology that does not provide interdisciplinarity, contextualization of content and does not generate any kind of encouragement to students. Thus, education has been the focus of great concern, which has fostered a revolution in the way that teachers are being trained. It is a pressing need to innovate, make use of new teaching strategies and employ new teaching tools. This year was implemented at SENAI in Jaragua do Sul a different methodology in restructured technical courses at SENAIsc: learning situations. A pedagogical practice
\end{abstract}


that brought significant results for students because it includes challenging activities, contextualized, and planned with clear evaluation criteria. In the process of teaching and learning the educator becomes, most of the time, mediator, and the student responsible for the appropriation of knowledge in a joint process of working: students, teachers and course and teaching coordinators. Thus, this article reports an experiment in technical courses in clothing and fashion production of the National Access to Technical Education and Employment (Pronatec), with the application of this methodology to the process of knowledge acquisition and learning evaluation supplanting the exams for students approval. It is noteworthy, however, that the results were significant since ensured the approval of all students and satisfaction of participating in the process.

Keywords: Learning. Learning situation. Pedagogical practice.

\section{REFERÊNCIAS}

BRISO, Caio Barreto et al. O desafio da escola: manter-se indispensável. Veja online, São Paulo, 25 mar. 2009. Disponível em: <http://veja.abril.com.br/noticia/educacao/ adiantamento-desafio-escola-manter-se-indispensavel>. Acesso em: 05 ago. 2012.

HANZE, Amelia. A aprendizagem para a qualidade de vida. Porto Alegre: UFRGS, 2007. Disponível em: <http://www6.ufrgs.br/psicoeduc/wiki/index.php/Aprendizagem_e_ Qualidade_de_Vida>. Acesso em: 31 ago. 2012.

PRADO, Maria Elisabette Brisola Brito. O papel do professor na criação de situações de aprendizagem. [S.I.: s.n.], 2012. Disponível em: <http://www.ich.pucminas.br/pged/ interact/viewfile.php/1/file/54/34/PDF.pdf>. Acesso em: 07 set. 2012.

SERVIÇO NACIONAL DE APRENDIZAGEM INDUSTRIAL. Departamento Nacional. Elaboração de perfis profissionais por comitês técnicos setoriais. 3. ed. Brasília, 2008. (Formação profissional baseada em competências ; 1)

Metodologias SENAI para formação profissional com base em competências: norteador da prática pedagógica. 3. ed. Brasília, 2009. (Formação profissional baseada em competências v. 3)

VALENTE, José Armando. Repensar as situações de aprendizagem: o fazer e o compreender. Boletim Salto para o Futuro, Brasília, 2002. Tecnologia e educação: novos tempos, outros rumos. Disponível em: <http://www.tvebrasil.com.br/salto>. Acesso em: 7 ago. 2012. 


\section{SOBRE AS AUTORAS}

\begin{tabular}{|c|c|c|}
\hline & $\begin{array}{l}\text { Pedagoga com habilitação em Orientação Educacional pela Universidade } \\
\text { Regional de Blumenau (FURB) e especialista em Consultoria empresarial } \\
\text { pela Universidade Federal de Santa Catarina (UFSC/SENAI) e em Negócios do } \\
\text { Vestuário pelo SENAI Blumenau/Jaraguá do Sul. Atuou na área de confecção } \\
\text { do vestuário como instrutora de treinamento na empresa Marisol Malhas. } \\
\text { Trabalhou também na rede municipal de ensino como docente na educação } \\
\text { de adultos. Atualmente é especialista em Vestuário no SENAI de Jaraguá do } \\
\text { Sul, onde já lecionou em unidades curriculares relacionadas à tecnologia } \\
\text { da costura, tecnologia da confecção, análise de produto, metodologia de } \\
\text { projetos nos cursos técnicos e no curso superior de Tecnologia em Produção } \\
\text { do Vestuário, assim como coordena e orienta trabalhos de conclusão de curso. } \\
\text { Atualmente é Coordenadora dos cursos técnicos em Produção de Moda, } \\
\text { técnico em Vestuário e técnico em Modelagem do Vestuário. }\end{array}$ \\
Souza &
\end{tabular}

\begin{tabular}{|l|l|l|} 
Engenheira Eletricista graduada pela Universidade Regional de Blumenau \\
(FURB) e Especialista em Automação Industrial pela Universidade do \\
Estado de Santa Catarina (UDESC). Atuou nas áreas de ensaios, assistência \\
técnica e vendas de drives na empresa WEG. Atualmente é especialista em \\
Eletroeletrônica no SENAI de Jaraguá do Sul, onde já lecionou em disciplinas \\
relacionadas à eletrônica, automação e robótica nos cursos técnicos de \\
eletrônica, eletrotécnica e Mecatrônica, no curso superior de Tecnologia \\
em Automação Industrial e no curso de Pós Graduação em Automação \\
Industrial, além de atuar como coordenadora de curso nos cursos técnicos em \\
Eletrotécnica e Mecatrônica e curso Superior em Automação Industrial. Dentro \\
da presente instituição também coordena e orienta trabalhos de conclusão de \\
curso para o curso Superior em Automação Industrial.
\end{tabular}

\begin{tabular}{|l|l|}
\hline & $\begin{array}{l}\text { Pedagogia com habilitação em Supervisão Escolar, Pós Graduada em } \\
\text { Administração de Recursos Humanos (FAE/UNERJ) e em Consultoria } \\
\text { Empresarial (UFSC/SENAI). Participou de mais de 1100 h/aula de capacitações e } \\
\text { treinamentos empresariais em diversas áreas de formação técnica profissional } \\
\text { e de relacionamento interpessoal. Atua, desde 1988, com a formação e o } \\
\text { desenvolvimento de lideranças, melhoria das relações humanas, resolução } \\
\text { de conflitos, melhoria nos métodos de trabalho e no ensino correto de um } \\
\text { trabalho. Atualmente, é instrutora no SENAI-SC, na unidade de Jaraguá do } \\
\text { Sul, ministrando as disciplinas de Comunicação Oral e Escrita, Metodologia } \\
\text { Científica, Metodologia da Pesquisa e Gestão de Processos. Desenvolve trabalho } \\
\text { de Consultoria Empresarial na área de gestão de pessoas e treinamento; } \\
\text { orienta TCCs nos cursos Técnicos e de Tecnologia; e, elabora materiais didáticos } \\
\text { para os cursos técnicos presenciais e a distância do SENAl. }\end{array}$ \\
\hline
\end{tabular}

